\title{
Protons and the hydrogen economy
}

\author{
Qianli Chen, State Key Laboratory of Metal Matrix Composites, University \\ of Michigan-Shanghai Jiao Tong University Joint Institute, Shanghai Jiao \\ Tong University, Shanghai 200240, China \\ Artur Braun, Laboratory for High Performance Ceramics, Empa. Swiss \\ Federal Laboratories for Materials Science and Technology, CH-8600 \\ Dübendorf, Switzerland; and Department of Mechanical Engineering, \\ Biomedical \& Energy Systems Laboratory, Yonsei University, Seoul 120-749, \\ Republic of Korea \\ Address all correspondence to Artur Braun at artur.braun@alumni.ethz.ch \\ (Received 9 August 2017; accepted 15 November 2017)
}

\section{ABSTRACT}

\section{As materials science is becoming components development and systems technology, hydrogen economy is approaching your porch. Welcome!}

Hydrogen mobility can now be purchased from the shelf. Fuel cell electric vehicles from various well-known car manufacturers are now available. The number of hydrogen filling stations in Europe is increasing at a rate that long-distance tours become less and less adventurous. The efforts of fuel cell researchers have paid off. Suppliers of components and systems for hydrogen infrastructure are anticipating business. Meanwhile, basic science in electrochemistry and materials research is continuing, with surprises such as the discovery of a proton polaron which are adding to the progress in fundamental understanding of energy materials in operation. Has the long awaited hydrogen economy finally arrived?

Keywords: hydrogenation; energy storage; neutron scattering

\section{DISCUSSION POINT}

- Hydrogen economy is not impeded by scientific or technological shortcomings. The challenge is only one of political, social, and ultimately mental nature. Competition against traditional energy carriers is the challenge.

\section{Introduction}

Hydrogen is, still, the most abundant matter in the universe. Unimaginably, astronomically long times warrant that physical processes with extremely small probability such as proton tunneling eventually manifest in the proton-proton reaction where two hydrogen nuclei approach each other so close that they melt into a deuterium nucleus and further react to a helium nucleus. Subsequent chain reactions cause radiative energy release in the $\mathrm{MeV}$ range. ${ }^{1,2}$

Our sun is a hotspot, one hundred million miles away in safe distance from the Earth, where the proton-proton reaction has taken place for 4 billion years and will continue so for the next 4 billion years to come. About $95 \%$ of our energy supply today on our planet derives from the energy which we receive from the sun. ${ }^{3}$

Given this size of the matter, is there any doubt that our current Terawatt Challenge ${ }^{4}$ can be met?

Access to energy is a precondition for economical welfare and for social welfare. While fossil fuels and nuclear power dominate world energy supply, renewable energy has an increasing share in the energy mix. Fear for global warming with gross scenarios such as a new mass extinction of species ${ }^{6}$ or flooding and droughts has helped increase efforts in sustainable development, and peer pressure by the sustainability movement helped to turn the direction. ${ }^{7}$ The world energy consumption is to $20 \%$ electric energy. The other $80 \%$ are provided by all kinds of fuels. With increasing electrification in our modern world, an increase of the share of electric energy to $>20 \%$ is anticipated. ${ }^{5}$ Such growth would be good news for the photovoltaic industry and business, and for wind and hydropower.

Would not it be great if still the $\mathbf{8 0 \%}$ of fuels (fossil, nuclear, biomass) could be produced by renewable energy? The idea of the hydrogen energy economy is almost 100 years old ${ }^{8}$ and is based on the calculation that transporting energy as $\mathrm{H}_{2}$ gas 
through pipes is less costly than by electricity running through electric cables. ${ }^{9,10}$

Artificial photosynthesis for the production of solar fuels, inspired by Ciamician over 100 years ago, ${ }^{11}$ took center stage in the early 1970s in response to the first Arab Oil Crisis. ${ }^{12}$ The interest in solar fuels faded away when oil prices came down again. With efforts in the space exploration programs in the 1950 s and 1960s, and the onset of the Green movement in the 1970s, fuel cell and battery research became part, and in the late 1980s the integral part of general energy research. ${ }^{5}$

The senior author of this commentary researched at Berkeley National Laboratory on lithium batteries and photosynthesis from 1999 to 2001. In the presidential election campaign 2000, George W. Bush emerged as an oil-friendly candidate. ${ }^{13}$ When George W. Bush was inaugurated in January 2001 as the 43rd President of the United States, some senior leading staff at LBNL expressed at one of our informal meetings their worries that "now we can forget about all of our fuel cell research funding."

To our surprise, only two years later, in his State of the Union address on 28 January 2003, ${ }^{14}$ President Bush announced "Tonight I am proposing $\$ 1.2$ billion in research funding so that America can lead the world in developing clean, hydrogenpowered automobiles."

The senior author of this paper spotted the first fuel cell electric vehicle (FCEV) in December 2010 on a Highway in Honolulustill loaded on a truck. ${ }^{15}$ In December 2016, the big picture ${ }^{16}$ of renewable energy condensed to a personal life experience when he had his first ride with a commercially available FCEV in Switzerland. By September 2017, he had a record of over $7500 \mathrm{~km}$ driven with hydrogen across Europe. He had been filling the FCEV at eleven different publically accessible hydrogen pumping stations in Belgium, Germany, and Switzerland. The infrastructure for such long distance travel is thus there. H2 Mobility in Berlin, a spin-off company from 11 global players, is aiming at operating 400 such $\mathrm{H} 2$ filling stations in Germany by $2023 .{ }^{17}$ Their mobile phone app H2.LIVE showed on 30 October, 2017, over $64 \mathrm{H} 2$ filling stations in operation, 59 of them were ready for filling, spanning ten countries from Scandinavia to Italy. Has hydrogen economy arrived? The Germans have already two large $\mathrm{H} 2$ pipeline systems in operation, the longest of which with $240 \mathrm{~km}$ at 25 bar pressure; they estimate that their $\mathrm{H} 2$ mobility infrastructure will cost 61 billion Euro. ${ }^{18}$ Given that the existing oil-based economy was not based on the principles of competitiveness, ${ }^{19}$ there will not be too hard feelings with continuing the renewable way.

In the 1930s, Franz Lawaczeck supposedly "pointed out that, due to the low viscosity of hydrogen, it would be cheaper to transport energy in the form of hydrogen in pipes rather than electricity in wires". ${ }^{8}$ Gregory et al. published a quantitative study in 1972 and also addressed the potential concerns about gas safety and compared with natural gas. ${ }^{10}$ At the macroscopic scale, transport properties of hydrogen and electrons do obviously play a role in the optimized "logistics" of energy. It sure does so at the microscopic scale, as we see later in this commentary. Storage and transport of energy in general and electric charge carriers in particular is essential for our modern society's needs for technology.

Lawaczeck likely considered $\mathrm{H}_{2}$ as fuel for transportation powered by combustion engines. Despite all advancement in modern combustion engine technology, such engines are subject to Carnot's fundamental thermodynamic limitation of efficiency. Electrochemical energy conversion in batteries and fuel cells is not subject to Carnot's limit and hence can be more efficient. A FCEV with $5.63 \mathrm{~kg} \mathrm{H}_{2}$ which you can fill in only 3 min can bring you as far as $600 \mathrm{~km}$ (at moderate speed), at a nominal price of around 50 Euros: this is the reality which the senior author of this commentary has tested over $7500 \mathrm{~km}$ in 10 months with hydrogen produced by local water power, local solar power, and as a side product from chemical industry, for example. This corresponds with the energy of almost $50 \mathrm{~L}$ of gasoline from crude oil which was shipped over the oceans. This sounds very promising even after reading Refs. 20 and 21 which favor battery powered vehicles. Is it still necessary to do the math when comparing these numbers? Given that such a car is sold for around 66,000 Euros, it easily outperforms the projections in Fig. 1 of Ref. 21. For sure, costs and prices for the FCEV will come down once larger number of cars are manufactured and sold.

The argument of higher thermodynamic efficiency is one reason why fuel cells have been further developed for automotive propulsion. Another reason for deploying fuel cells is that they do not produce air pollution, in contrast to combustion engines, and they run on hydrogen from renewable energy.

One scientifically trivial but important technical detail in electromobility technology is that it is not only the electrons which bring about the electromotoric force necessary to power the electric motor but also the ions, particularly protons $\mathrm{H}^{+}$in the fuel cells and lithium $\mathrm{Li}^{+}$in the batteries, which are stored as chemical energy in the hydrogen fuel and in the battery electrodes, respectively.

The electron is a well-understood charge carrier in condensed matter physics. Its transport behavior in the wellconducting metals was first described by Drude. ${ }^{22}$ Drude used kinetic gas theory for the derivation of the equation of motion of "free electrons"-a somewhat stretched approximation which describes the reality surprisingly well not only for electrons but also for electron holes $\mathrm{h}^{+}$-the positive charge carriers.

While Drude's model is based on the concept of the free electron gas where the conductivity of the metal conductor is not influenced by mutual interaction of the conducting electrons, the interaction of these electrons in fact takes place. Such an interaction manifests in the temperature dependency of the conductivity. At very low temperature, some metals show superconductivity-a quantum effect. With the increasing temperature, the electrons interact increasingly with each other and with the atoms, thus decreasing the conductivity. It has been therefore of technological interest to minimize such losses by enhancing the conductivity. Lowering the operation temperature to reach superconductivity is as important as identifying new materials that will be superconducting at a temperature as 
close as possible to ambient operation temperature. The electric transport properties of materials are determined by their electronic structure. Thermal excitations of the crystal lattice produce phonons (coherent vibrations of the lattice) which couple to the electrons and form charge carrier excitations, the polarons. They are noticeable because of the exponential increase of the conductivity upon rising temperature.

When electrochemical energy storage and conversion come into play, the chemical reactions of the redox partners ${ }^{20}$ require that we consider also ions as charge. Ionic transport in liquid electrolytes is popular in knowledge. It can be rationalized as frequent hopping of ions. Ions diffuse and migrate in condensed matter, too. For fuel cells and solid state batteries, we consider here the ion transport in solids.

Some solids show very high ionic conductivity. Such fast ion conductors are interesting materials for electrolyte membranes in ceramic fuel cells, electrolyzers, and solid state batteries. ${ }^{23}$

With respect to hydrogen as solar fuel and its use in electrolyzers and fuel cells, proton conducting membranes are interesting. ${ }^{24,25}$ They operate at around $400{ }^{\circ} \mathrm{C}$, whereas oxygen ion conductors operate at $800{ }^{\circ} \mathrm{C}$.

Because proton conductivity in such membranes is a temperature activated process, improving them requires understanding the nature of proton transport. In doing so a surprise awaited
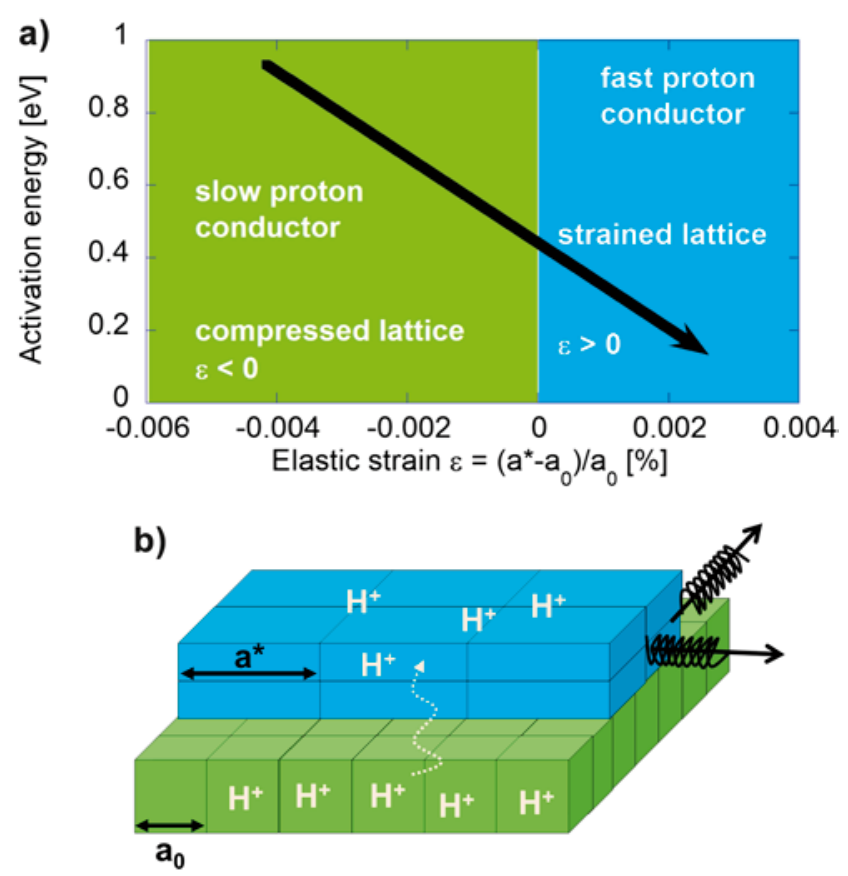

Figure 1. (a) Variation of activation energy versus the elastic strain parameter $\varepsilon$ for a proton conductor membrane. (b) The film (blue) has larger lattice parameter $a^{*}$ than the support material (green) with lattice parameter $a_{0}$, as the film is tensile strained with respect to the support layer. Tensile strain is illustrated by arrows inside spring coils. Protons $\mathrm{H}^{+}$ move easier through the film than through the substrate. Tensile strain should be used to reduce the activation energy. us, as we found polaron-like transport behavior for the proton, ${ }^{26}$ hitherto not known in solid-state science. ${ }^{27}$ Remarkably, some pioneering ideas about proton polarons were developed for biomembranes in photosynthesis. ${ }^{28}$

Due to the remarkable way protons and vibrations of the atoms interact, which produces such proton polarons, there is promise that one can push the operation temperature of the all-important proton conducting membrane further down to close to ambient temperature, if they are grown very thin under strain. ${ }^{29-31}$ Figure 1 illustrates how the activation energy for proton conductivity decreases linearly with the strain parameter in compressed proton conductors. Extrapolation to tensile strained materials such as in epitaxial films could lower the activation energy to $0.2 \mathrm{eV}$ or below.

We feel that there is potential for improvement of proton conductivity beyond the state-of-the-art, with the potential of making electrochemical energy systems even more attractive than hitherto known.

\section{Acknowledgment}

During the preparation of this manuscript, A.B. was on leave to Yonsei University funded by the Swiss National Science Foundation project IZK0Z2-175249. Funding by NanoTera SHINE project no ${ }^{\circ}$ 20NA21-145936 is acknowledged.

\section{REFERENCES:}

1. Bertulani C.A. and Kajino T.: Frontiers in nuclear astrophysics. Prog. Part. Nucl. Phys. 89, 56 (2016).

2. Adelberger E.G., García A., Robertson R.G.H., Snover K.A., Balantekin A.B., Heeger K., Ramsey-Musolf M.J., Bemmerer D., Junghans A., Bertulani C.A., Chen J.W., Costantini H., Prati P., Couder M., Uberseder E., Wiescher M., Cyburt R., Davids B., Freedman S.J., Gai M., Gazit D., Gialanella L., Imbriani G., Greife U., Hass M., Haxton W.C., Itahashi T., Kubodera K., Langanke K., Leitner D., Leitner M., Vetter P., Winslow L., Marcucci L.E., Motobayashi T., Mukhamedzhanov A., Tribble R.E., Nollett K.M., Nunes F.M., Park T.S., Parker P.D., Schiavilla R., Simpson E.C., Spitaleri C., Strieder F., Trautvetter H.P., Suemmerer K., and Typel S.: Solar fusion cross sections. II. Theppchain and CNO cycles. Rev. Mod. Phys. 83, 195 (2011).

3. IEA: Key World Energy Statistics 2017 (IEA-International Energy Agency, Paris, 2017). Available at: https://www.iea.org/publications/ freepublications/publication/KeyWorld2017.pdf.

4. Smalley R.E.: Future global energy prosperity: The terawatt challenge. MRS Bull. 30, 412 (2011).

5. Thapper A., Styring S., Saracco G., Rutherford A.W., Robert B., Magnuson A., Lubitz W., Llobet A., Kurz P., Holzwarth A., Fiechter S., de Groot H., Campagna S., Braun A., Bercegol H., and Artero V.: Artificial photosynthesis for solar fuels-An evolving research field within AMPEA, a joint programme of the european energy research alliance. Green 3, 43 (2013).

6. Barnosky A.D.: Transforming the global energy system is required to avoid the sixth mass extinction. MRS Energy Sustain. 2, E10 (2015).

7. Priddy R.D.: Sustainability: The train has left the station. MRS Energy Sustain. 4, E3 (2017).

8. Bockris J.: The origin of ideas on a hydrogen economy and its solution to the decay of the environment. Int. J. Hydrogen Energy 27, 731 (2002).

9. Gregory D.P.: Electrochemistry and the Hydrogen Economy, Mod. Aspect. Electroc. 10, 239 (1975).

10. Gregory D.P., Ng D.Y.C., and Long G.M.: The hydrogen economy. In Electrochemistry of Cleaner Environments, Bockris J.O., ed. (Springer, Boston, MA, 1972); p. 226. 
11. Ciamician G.: The photochemistry of the future. Science 36,385 (1912).

12. Eden R.: Review of the book "the Arabs and the oil crisis 1973-1986"Authored by OAPEC secretary general Ali A. Attiga. Energy Policy 16, 330 (1988).

13. Seelye K.Q.: The 2000 Campaign: The Texas Governor; Bush Would Use Power of Persuasion to Raise Oil Supply, in New York Times (The New York Times Company, New York, 2000).

14. Bush G.W.: President delivers. In State of the Union, Secretary O.o.t.P., ed. (Office of the Press Secretary, U.S. Capitol, 2003).

15. Motavalli J.: Hawaii's Synergy: New Hydrogen Stations + GM Fuel-Cell Cars, in CBS News (CBS Interactive Inc., New York, 2010).

16. Ginley D.S., Cahen D., and Kócs E.A.: The big picture - accepting diverse views on energy and sustainability. MRS Energy Sustain. 3, E2 (2016).

17. Shell: Shell to install nationwide network of hydrogen vehicle fuelling pumps in Germany (2015). Available at: http://www.shell.com/media/ news-and-media-releases/2015/shell-to-install-nationwide-networkhydrogen-vehicle-fuelling-pumps-germany.html (accessed November 13, 2017).

18. Emonts B., Schiebahn S., Görner K., Lindenberger D., Markewitz P., Merten F., and Stolten D.: Re-energizing energy supply: Electrolyticallyproduced hydrogen as a flexible energy storage medium and fuel for road transport. J. Power Sources 342, 320 (2017).

19. Olson C. and Lenzmann F.: The social and economic consequences of the fossil fuel supply chain. MRS Energy Sustain. 3, E6 (2016).

20. Hermans J.: The challenge of energy-efficient transportation. MRS Energy Sustain. 4, E2 (2017).

21. Liu P., Ross R., and Newman A.: Long-range, low-cost electric vehicles enabled by robust energy storage. MRS Energy Sustain. 2, E12 (2015).
22. Drude P.: Zur Elektronentheorie der Metalle. Ann. Phys. 306, 566 (1900).

23. Mahato N., Banerjee A., Gupta A., Omar S., and Balani K.: Progress in material selection for solid oxide fuel cell technology: A review. Prog. Mater. Sci. 72, 141 (2015).

24. Kreuer K-D.: Proton conductivity: Materials and applications. Chem. Mater. 8, 610 (1996).

25. Norby T., Widerøe M., Glöckner R., and Yngve L.: Hydrogen in oxides. Dalton Trans. 19, 3012 (2004).

26. Samgin A.L.: Lattice-assisted proton motion in perovskite oxides. Solid State Ionics 136, 291 (2000).

27. Braun A. and Chen Q.: Experimental neutron scattering evidence for proton polaron in hydrated metal oxide proton conductors. Nat. Commun. 8, 15830 (2017).

28. Tomchuk P.M., Protsenko N.A., and Krasnogolovets V.V.: Functioning of proton-conducting channels in biomembranes. Biol. Membr. 1, 1171 (1984).

29. Chen Q., Huang T-W., Baldini M., Hushur A., Pomjakushin V., Clark S., Mao W.L., Manghnani M.H., Braun A., and Graule T.: Effect of compressive strain on the Raman modes of the dry and hydrated $\mathrm{BaCe}_{0.8} \mathrm{Y}_{0.2} \mathrm{O}_{3}$ proton conductor. J. Phys. Chem. C 115, 24021 (2011).

30. Chen Q.L., Braun A., Yoon S., Bagdassarov N., and Graule T.: Effect of lattice volume and compressive strain on the conductivity of BaCeY-oxide ceramic proton conductors. J. Eur. Ceram. Soc. 31, 2657 (2011).

31. Chen Q.L., Braun A., Ovalle A., Savaniu C.D., Graule T., and Bagdassarov N.: Hydrostatic pressure decreases the proton mobility in the hydrated $\mathrm{BaZr}_{0.9} \mathrm{Y}_{0.1} \mathrm{O}_{3}$ proton conductor. Appl. Phys. Lett. 97, 041902 (2010). 